\title{
Lung retransplantation for chronic lung allograft dysfunction
}

\author{
Monika Kosiorowska ${ }^{1}$, Bartosz Kubisa ${ }^{1}$, Mikołaj Górski ${ }^{1}$, Maria Piotrowska ${ }^{1}$, Michał Kubisa ${ }^{1}$, \\ Mirosław Brykczyński ${ }^{2}$, Małgorzata Wojtyś ${ }^{1}$, Jarosław Pieróg ${ }^{1}$, Michalina Czarnecka ${ }^{1}$, Janusz Wójcik ${ }^{1}$, \\ Norbert Wójcik ${ }^{1}$, Michał Bielewicz ${ }^{1}$, Piotr Sielicki ${ }^{2}$, Tomasz Grodzki ${ }^{1}$ \\ ${ }^{1}$ Department of Thoracic Surgery and Transplantation, Pomeranian Medical University, Szczecin, Poland \\ ${ }^{2}$ Department of Cardiac Surgery, Pomeranian Medical University, Szczecin, Poland
}

Kardiochir Torakochir Pol 2019; 16 (3): 136-137

Lung transplantation (LTx) is currently the best therapeutic option for patients with end stage lung disease. Technical progress in graft procurement and implantation, perioperative care, or individual management and better immunosuppression therapy monitoring of patients after transplantation, resulted in a significant improvement in recipients' survival. Together with the increase in the survival rate of patients after transplantation, the number of retransplantations has increased. Currently, lung retransplantations (ReLTX) account for approximately $5 \%$ of all lung transplantations [1]. Chronic lung allograft dysfunction (CLAD) is a major complication of LTX, leading to a substantial decrease in the survival rate of recipients and a significant deterioration of their quality of life [2]. Two major subtypes of CLAD have been described: bronchiolitis obliterans syndrome (BOS) and restrictive allograft syndrome (RAS). Chronic rejection usually takes the form of BOS. This brief case description documents a left lung retransplantation due to CLAD-BOS with subsequent right-sided pneumonectomy as a result of the failure of the previous graft.

We present a case of a 43-year-old man with respiratory failure in the course of chronic dysfunction of lungs. The patient had been diagnosed with many chronic conditions, such us post-transplantation renal insufficiency, post-transplantation diabetes (PTD), exocrine pancreatic insufficiency, and osteopenia. In 2014, 4 years prior to the described events, the patient underwent lung transplantation due to the advancement and progression of cystic fibrosis. He was operated on in a different European lung transplantation center. The early and late post-transplantation periods were complicated by chronic infection with Pseudomonas aeruginosa and Pneumocystis jiroveci in 2015 and 2016. From March 2016, there was a gradual deterioration of breathing. The biopsy revealed chronic graft rejection with the BOS 1 subtype (forced expiratory volume in 1 second $\left(\mathrm{FEV}_{1}\right) 80 \%$ ); therefore, steroid therapy was administered. Six months later, the patient's condition deteriorated, with a significant impairment of $F E V_{1}$, requiring antithymocyte globulin ATG and further extracorporeal photopheresis treatment. In 2017 the patient developed oxygen-dependent respiratory failure with a rapidly decreasing $\mathrm{FEV}_{1}$ from $60 \%$ to $40 \%$. As a consequence, the patient was successfully qualified for lung retransplantation. In October 2018, the patient underwent retransplantation of the left lung at our center. Veno-arterial extracorporeal membrane oxygenation (ECMO) with peripheral cannulation was commenced owing to the expected chest adhesions. After surgical exposure via a clamshell incision through the previous scar, the anatomical structures were difficult to identify. The preparation was started from the left lung. Because of the existing difficult anatomical conditions and thus the prolonged ischemic time for the first lung (11 hours), the transplantation of the second lung was cancelled (Figure 1). The patient was then transferred to the intensive care unit (ICU) and extubated on the third postoperative day. Due to postoperative renal failure on the first day after retransplantation, the patient required renal replacement therapy. On the $10^{\text {th }}$ postoperative day, it was decided to perform pneumonectomy of the right lung, due to increasing dyspnoea and significant pulmonary leakage in the previous graft. During ICU stay, on the $17^{\text {th }}$ day after retransplantation, because of the persistent postoperative bleeding into the post-resection cavity, rethoracotomy with a successful hemostatic effect was performed. The patient was discharged home on the 66th postoperative day (Figure 2). In a two-month follow-up, the patient was in a good overall condition with progressive improvement of respiratory function and $\mathrm{FEV}_{1}$.

Retransplantation remains a life-saving procedure for CLAD-BOS. It is the most effective, but on the other hand, it is very risky and associated with a significantly reduced, compared to first transplantation, recipient's survival rate. Recent studies have shown that ReTx is associated with increased perioperative mortality and morbidity and

Address for correspondence: Monika Kosiorowska MD, Department of Thoracic Surgery and Transplantation, Pomeranian Medical University, 11 Sokołowskiego St, 70-891 Szczecin-Zdunowo, Poland, phone: +48 607590 891, fax: +48 9146208 36, e-mail: kosiorowska.mm@gmail.com Received: 19.04.2019, accepted: 10.08.2019. 


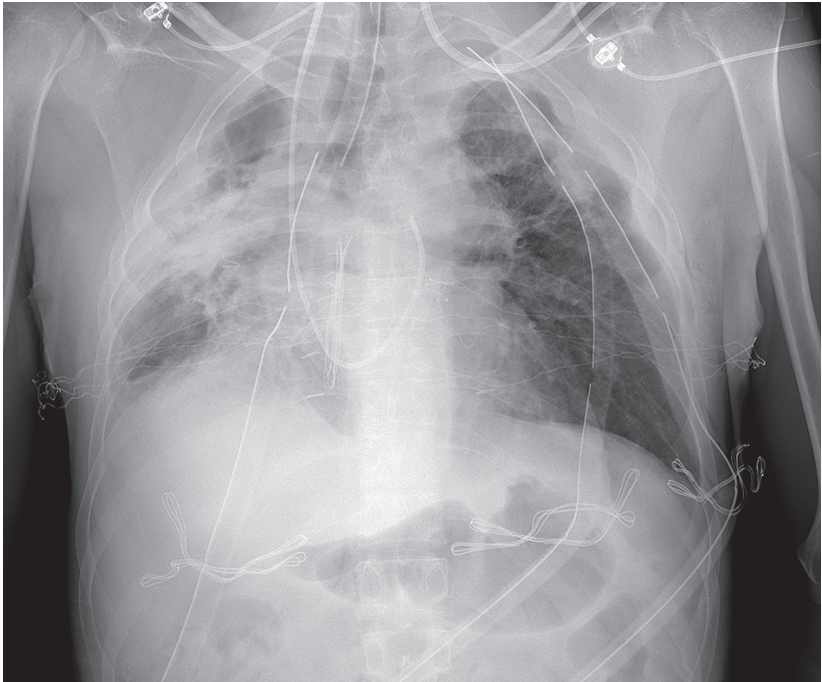

Figure 1. Chest X-ray after left lung retransplantation

a shorter survival rate compared to primary LTx [3]. CLAD is associated with increased costs of hospital treatment. The cumulative risk of occurrence of BOS in the 10-year posttransplantation period reaches $80 \%$ [4]. Novick et al. presented a retrospective analysis of 72 patients who had undergone retransplantation for BOS. In the analyzed group the survival rate for one month, one year and two years was $71 \%, 43 \%$ and $35 \%$ [5]. Brugière et al. carried out a longterm analysis of 15 patients undergoing retransplantation due to BOS. All cases concerned single lung transplantation whereas two patients had undergone dual primary lung transplantation. Their survival rate at 1, 2, and 5 years after retransplantation was $60 \%, 53 \%$, and $45 \%$, respectively [4]. Analysis of five smaller studies conducted by Christie et al. for patients with BOS after ReLTx showed a survival rate at 1 and 5 years of approximately $60-75 \%$ and $44-62 \%$ [6]. This short report presents the first lung retransplantation for BOS performed in our institution. Due to difficult conditions during retransplantation, which caused prolonged ischemia time of the graft, it was decided not to transplant the second lung. Retransplantation is a controversial choice of therapy; however, it is necessary to consider it for patients with BOS. It should be remembered that ReLTX patients are more time-consuming, require extraordinary attention and are associated with a significantly increased risk of serious complications. We hope that this report will contribute to other institutions' awareness that such cases require the involvement of a team of specialists with ad-

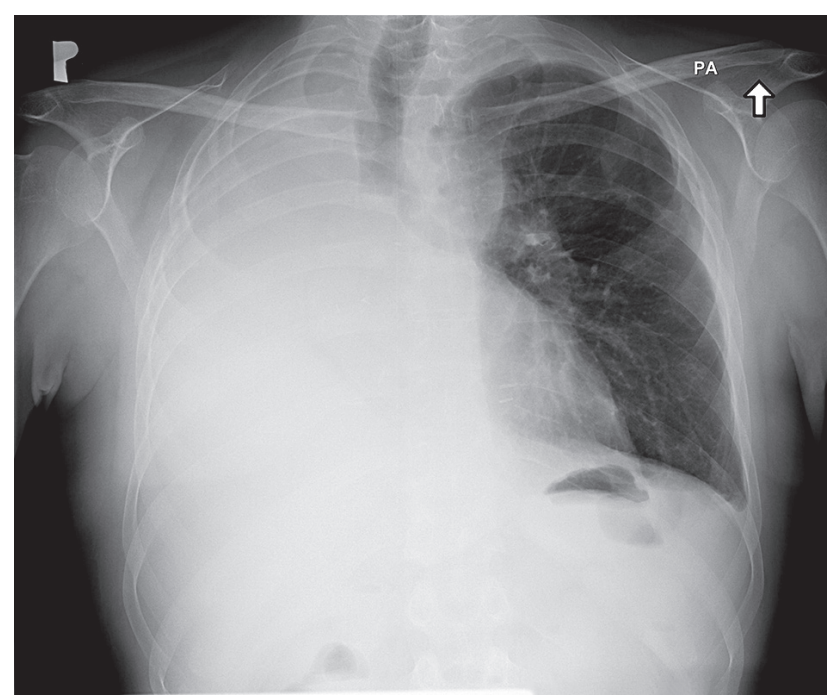

Figure 2. Chest X-ray 1 month after rethoracotomy

equate coordination and careful time management in order to adjust in 10-12 hours of ischemia time. This will directly improve the outcome of the procedure, and thus help to avoid serious postoperative complications.

\section{Disclosure}

The authors report no conflict of interest.

\section{References}

1. Yusen RD, Edwards LB, Kucheryavaya AY, Benden C, Dipchand Al, Dobbels F, Goldfarb SB, Levvey BJ, Lund LH, Meiser B, Stehlik J; International Society for Heart and Lung Transplantation. The registry of the international society for heart and lung transplantation: thirty-first adult lung and heart-lung transplant report. J Heart Lung Transplant 2014; 33: 1009-1024.

2. Vermeulen KM, Groen H, van der Bij W, Erasmus ME, Koëter GH, TenVergert EM. The effect of bronchiolitis obliterans syndrome on health related quality of life. Clin Transplant 2004; 18: 377-383.

3. Ren D, Kaleekal TS, Graviss EA, Nguyen DT, Sinha N, Goodarzi A, Agboli I, Suarez EE, Loebe M, Scheinin SA, Bruckner BA. Retransplantation outcomes at a large lung transplantation program. Transplant Direct 2018; 4: e404.

4. Brugière O, Thabut G, Castier Y, Mal H, Dauriat G, Marceau A, Lesèche G. Lung retransplantation for bronchiolitis obliterans syndrome: long-term follow-up in a series of 15 recipients. Chest 2002; 123: 1832-1837.

5. Novick RJ, Schäfers HJ, Stitt L, Andréassian B, Duchatelle JP, Klepetko W, Hardesty RL, Frost A, Patterson GA. Recurrence of obliterative bronchiolitis and determinants of outcome in 139 pulmonary retransplant recipients. J Thorac Cardiovasc Surg 1995; 110: 1402-1413.

6. Christie JD, Edwards LB, Kucheryavaya AY, Aurora P, Dobbels F, Kirk R, Rahmel AO, Stehlik J, Hertz MI. The Registry of the International Society for Heart and Lung Transplantation: twenty-seventh official adult lung and heart-lung transplant report. J Heart Lung Transplant 2010; 29: 1104-1118. 